\title{
Improved biocompatibility of novel poly(L-lactic acid)/ $\beta$-tricalcium phosphate scaffolds prepared by an organic solvent-free method
}

This article was published in the following Dove Press journal:

International Journal of Nanomedicine

I July 201 I

Number of times this article has been viewed

\author{
Xue-Feng Zhao ${ }^{1,2}$ \\ Xiao-Dong $\mathrm{Li}^{3}$ \\ Yun-Qing Kang ${ }^{4}$ \\ Quan Yuan ${ }^{1,2}$
}

'State Key Laboratory of Oral diseases, Sichuan University, Chengdu, People's Republic of China;

${ }^{2}$ West China School of Stomatology,

Sichuan University, Chengdu,

People's Republic of China;

${ }^{3}$ Affiliated Hospital of Stomatology and

College of Stomatology, Chongqing

Medical University, Chongqing,

People's Republic of China;

${ }^{4}$ College of Materials Science and

Engineering, Sichuan University,

Chengdu, People's Republic of China

\begin{abstract}
A porous poly(L-lactic acid)/ $\beta$-tricalcium phosphate (PLLA/ $\beta$-TCP) composite scaffold was fabricated using a novel technique comprising powder mixing, compression molding, low-temperature treatment, and particulate leaching without any organic solvent. The effect of this scaffold on osteoblast proliferation and differentiation was evaluated in vitro. The fabricated scaffold had a homogeneously interconnected porous structure with a porosity of $70 \%$ and compressive strength of $1.35 \mathrm{MPa}$. The methylthiazol tetrazolium values and alkaline phosphatase (ALP) activity of osteoblasts seeded on the solvent-free scaffold were significant higher than those of the control. Using real-time PCR, gene expressions of ALP, osteocalcin, and type 1 collagen were shown to be upregulated. As the method does not use any organic solvent, it eliminates problems associated with organic solvent residue and therefore improves the cell compatibility. It has a promising potential for the preparation of porous scaffold for bone tissue engineering.
\end{abstract}

Keywords: biocompatibility, biomaterials, composites, poly(L-lactic acid), $\beta$-tricalcium phosphate

\section{Introduction}

The repair of bone defects is of key interest in orthopedics and in dental implant treatment. Although some ceramics such as hydroxyapatite and tricalcium phosphate ( $\beta$-TCP) are currently available as bone graft substitutes, none has been demonstrated to be fully satisfactory. ${ }^{1}$ The brittleness of calcium phosphate ceramics confines them to nonload or low-load bone repairs. Poly(L-lactic acid) (PLLA) is also extensively used for the regeneration of bone tissue, because of its biocompatibility and biodegradation. ${ }^{2}$ However, the acid degradation products of PLLA can result in aseptic inflammation of tissues, and the hydrophobicity of PLLA may significantly affect cell attachment ability. An approach to overcome these limitations is the use of ceramic-polymer composite materials. ${ }^{2-4}$

Several methods have been reported to prepare porous composite scaffolds, such as porogen leaching, ${ }^{5}$ thermally induced phase separation, ${ }^{6}$ and freeze-extraction and freeze-gelation methods. ${ }^{7}$ However, in these methods, a large number of organic solvents and surfactants are used which form residues in the composite scaffolds. These residual organic solvents and surfactants have the potential to harm cell and tissue. ${ }^{8}$ Furthermore, in these methods, the polymer is usually dissolved in an organic solvent and then the ceramic particles are added. After the solvent is volatilized, the ceramic particles are usually coated by polymer, which leads to the hydrophobic surface of the scaffold.
Correspondence: Quan Yuan State Key Laboratory of Oral Diseases, Sichuan University, 14 Third Section, Renmin Nan Road, Chengdu 61004I, People's Republic of China

Tel +862885503579

Fax +86288550I427

Email yuanquan@scu.edu.cn 
To solve the problems of residual organic solvent and cell compatibility, we previously demonstrated a novel technique comprising powder mixing, compression molding, low-temperature treatment, and particulate leaching (PCLP) to prepare PLLA/ $\beta$-TCP composite scaffolds without using any organic solvent. ${ }^{9}$ But in the previous study, the in vitro biological evaluation of the scaffold prepared by this novel method was not comprehensively investigated. Therefore, we further studied the effect of this composite scaffold on in vitro osteoblast proliferation and differentiation, compared with that of scaffolds made by the conventional solvent casting method.

\section{Experimental}

\section{Preparation of PLLA $/ \beta$-TCP scaffold}

The PLLA/ $\beta$-TCP scaffold was prepared by the PCLP method reported previously with minor modification. ${ }^{9}$ Briefly, PLLA and $\beta$-TCP (diameter: $\mathrm{D}_{\mathrm{av}}=1.31-2.34 \mu \mathrm{m}$ ) were mixed together $(50: 50, \mathrm{w} / \mathrm{w})$, and further homogeneously mixed with sieved sodium chloride (porogen, diameter: 200-400 $\mu \mathrm{m}$ ) by magnetic force stirring for 30 minutes before loading into a disk mold (inner diameter: $13 \mathrm{~mm}$ ). PLLA $\left(\mathrm{M}_{\mathrm{w}}: 600 \mathrm{kDa}\right)$ was purchased from Chengdu Organic Chemicals Co. Ltd., Chinese Academy of Sciences. The weight ratio of salt particulates to compounds (PLLA and $\beta$-TCP) used was $2.4: 1$, ie, the percentage of salt in the total mixture weight was $70.59 \%$. After the mixture and stainless steel mold were heated at $170^{\circ} \mathrm{C}$ for 10 minutes, and the mixture in mold was quickly pressed at a pressure of $10 \mathrm{MPa}$ for 5 minutes to yield a solid disc. Next, the prepared composite disc was further heated at $200^{\circ} \mathrm{C}$ for 30 minutes with conversion every 5 minutes during the heating period. The sodium chloride particulates were subsequently removed from the composites by leaching the composites in distilled water with shaking for 72 hours, with water changed every 6 hours until no precipitation occurred by adding silver nitrate into the changed water. The composites were then dried in a vacuum oven for further use. For the control experiments, composites were fabricated by conventional solution casting/film crushing/compression molding/particulate leaching method from $5 \% \mathrm{w} / \mathrm{v}$ chloroform solution.

\section{Scaffold characterization}

Scaffold porosity was measured using the Archimedes immersion technique as described previously. ${ }^{10}$ Scaffold pore diameter and morphology were observed with a scanning electron microscopy (SEM) (FEI Inspect F, The Netherlands) after gold coating. The compressive strength of the scaffold was evaluated on an AG-10TA electronic apparatus (Shimadzu, Japan).

\section{Primary culture of calvarial osteoblasts}

Osteoblastic cells were enzymatically isolated from neonatal Sprague-Dawley rats as described preciously. ${ }^{11}$ Briefly, dissected calvariae were sequentially digested for 10-minute intervals with $0.1 \%$ type I collagenase (Sigma-Aldrich, St Louis, Mo) and $0.25 \%$ trypsin (Sigma-Aldrich) at $37^{\circ} \mathrm{C}$. Cells obtained from the second to the fourth digestions were incubated in DMEM (Gibco) with antibiotics and 10\% fetal bovine serum (Gibco). At about 90\% confluence, cells were trypsinized and subcultured. To confirm that cultures were osteoblast-enriched, mineralized bone nodule formation assay and alkaline phosphatase (ALP) staining were performed. All experiments were performed using the cells of third passage.

\section{Scanning electron microscopy}

Cell suspension $\left(3 \times 10^{4}\right.$ cells $/ \mathrm{mL}, 1 \mathrm{~mL} /$ well $)$ were pipetted on to scaffolds in the 24 -well plates and incubated at $37^{\circ} \mathrm{C}$. After 24 hours, cell morphology was visualized using an SEM (FEI Inspect F, The Netherlands). Scaffolds attached with cells were fixed in $2.5 \%$ glutaraldehyde, dehydrated, and sputter coated with gold/palladium prior to SEM observation.

Table I Specific primers designed following the cDNA sequences of each gene in GenBank

\begin{tabular}{|c|c|c|c|}
\hline Gene & $\begin{array}{l}\text { GenBank accession } \\
\text { number }\end{array}$ & Primers & Product size \\
\hline \multirow[t]{2}{*}{ ALP } & NM_0I3059 & (+), 5'-CGTCTCCATGGTGGATTATGCT-3' & 209 bp \\
\hline & & $(-), 5^{\prime}$-CCCAGGCACAGTGGTCAAG-3' & \\
\hline \multirow[t]{2}{*}{$\mathrm{OCN}$} & NM_013414 & $(+), 5^{\prime}$-TACCTCAACAATGGACTTGGAGC-3' & 206 bp \\
\hline & & $(-), 5^{\prime}$-CTGGAGAGTAGCCAAAGCTGAAG-3' & \\
\hline \multirow[t]{2}{*}{ COL-I } & XM_213440 & $(+), 5^{\prime}$-GCATGGCCAAGAAGACATCC-3' & 239 bp \\
\hline & & $(-), 5^{\prime}$-CTCCTATGACTTCTGCGTCTGGT-3' & \\
\hline \multirow[t]{2}{*}{$\beta$-Actin } & NM_03II44 & $(+), 5^{\prime}$-CACGGCATTGTCACCAACTG-3' & 167 bp \\
\hline & & $(-), 5^{\prime}$-TTGAAGGTCTCAAACATGATCTGG-3' & \\
\hline
\end{tabular}




\section{Assessment of cell proliferation}

Cell proliferation was assessed using a methylthiazol tetrazolium (MTT, Sigma-Aldrich) method. Briefly, $50 \mu \mathrm{L}$ MTT solution $(5 \mathrm{mg} / \mathrm{mL})$ was added to each well, followed by incubation for 4 hours at $37^{\circ} \mathrm{C}$. The medium and MTT were then replaced by $1 \mathrm{~mL}$ dimethyl sulfoxide to dissolve the formazan crystals. After 30 minutes, $200 \mu \mathrm{L}$ of supernatant was transferred to microplate wells (Falcon), and the optical density was quantified at a wavelength of $492 \mathrm{~nm}$ (HTS 7000 plus, PerkinElmer, USA).

\section{Measurement of ALP activity}

ALP activity was determined in cell homogenates prepared by ultrasonication, with an ALP diagnostic reagent of p-nitrophenyl phosphate (Merit Choice Co. Ltd. Beijing, China). The absorbance of p-nitrophenol formed by the hydrolysis of p-nitrophenyl phosphate was measured at $405 \mathrm{~nm}$ 3 times every 10 minutes. Total protein content was measured with the Bradford method. ALP activity was then normalized to its protein concentration and expressed as units/g protein.

\section{RNA extraction and quantitative real-time PCR}

Total RNA was extracted from each sample by the TRIzol method strictly following the manufacturer's protocol (Invitrogen, Carlsbad, CA.). The first-strand cDNA was synthesized from $1 \mu \mathrm{g}$ RNA with murine leukemia virus reverse transcriptase (Takara, Japan), and used for quantitative real-time PCR. Expression levels of representative genes, including ALP, osteocalcin (OCN), and type 1 collagen (COL-1), were quantified with an ABI 7300 realtime PCR system (Applied Biosystems, Foster City, CA) and SYBR green PCR reaction mix (Infinigen, USA). Primers and annealing temperature for each gene are listed in Table 1. The program used was: $50^{\circ} \mathrm{C}$ for 2 minutes, $95^{\circ} \mathrm{C}$ for 10 minutes, 40 cycles of $95^{\circ} \mathrm{C}$ for 15 seconds, and annealing temperature for 1 minute. Melting analysis and agarose gel electrophoresis were performed to confirm the specificity of the PCR products. The relative expression levels of genes were analyzed using the $2^{-\Delta \Delta \mathrm{Ct}}$ method by normalizing with $\beta$-actin housekeeping gene expression, and presented as fold increase relative to the control group.

\section{Statistical analysis}

Data are shown as means \pm standard deviation, and were statistically compared using independent-samples $t$ tests. Differences at $P<0.05$ were considered statistically significant.

\section{Results and discussion}

Figure 1A shows the interconnected pore structure of PCLP scaffold made by the organic solvent-free method. The Archimedes immersion technique showed the porosity of the PCLP scaffold to be around $70 \%$. Scaffold porosity and pore size are important features for evaluating biomaterial properties for tissue engineering. Sufficient pore size allows maximum osteoconduction with sufficient nutrient transfer for optimal tissue growth, although there are conflicting reports on the pore size that favors new bone formation and growth ${ }^{12-14}$ The porosity and pore structure can be controlled by salt weight, particulate size, and polymer fraction. Our previous study indicated that scaffold porosity increases with increasing sodium chloride particulate size. However, the compressive strength of PLLA $/ \beta$-TCP scaffold decreased with increasing porosity. ${ }^{9}$ Therefore, we used the sieved sodium chloride with a particulate size of $200-400 \mu \mathrm{m}$ and weight ratio of $70.59 \%$ to prepare the composites. As shown in Figure 2, the compressive strength of PCLP scaffold was $1.35 \mathrm{MPa}$, significantly higher than that of solvent-casting composites. This result indicates that the conditions used in the current study could achieve a highly porous scaffold with uncompromised compressive strength.

Figure 3 shows the morphological features of osteoblasts cultured on the scaffolds for 1 day. The osteoblasts attached and spread on the surface well. SEM images indicate that more cells were presented in the PCLP scaffolds together with more distinguishable and typical cell shape. Cells extend filopodia to the surface of PCLP scaffolds, and multiple point attachments were observed.

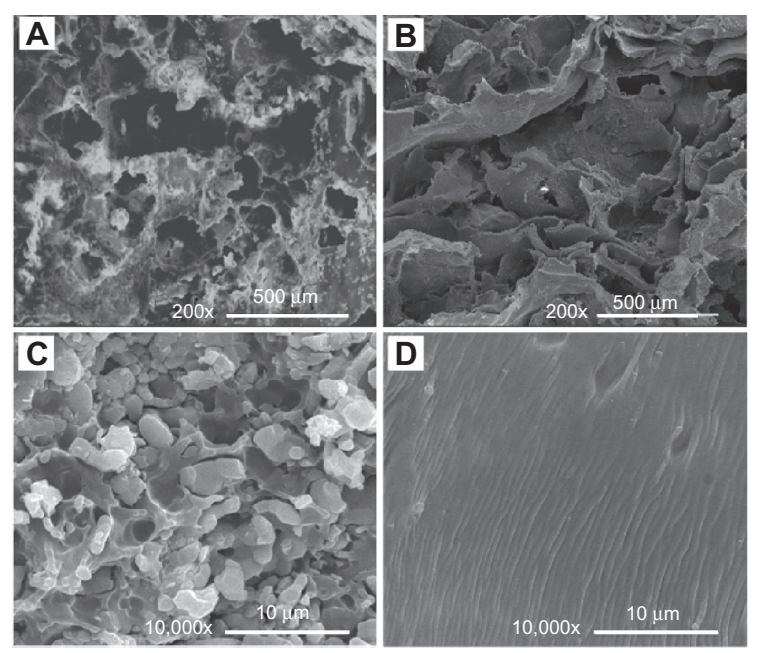

Figure I SEM images of scaffolds made by PCLP method $(\mathbf{A}, \mathbf{C})$ and by conventional organic solvent casting method (B, D).

Abbreviations: PCLP, powder mixing, compression molding, low-temperature treatment, and particulate leaching; SEM, scanning electron microscopy. 


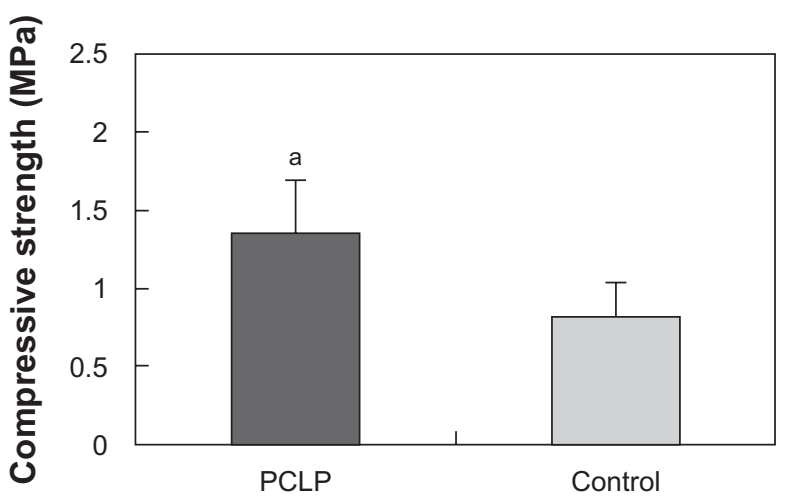

Figure 2 Compressive strength of scaffolds. Notes: ${ }^{a} P<0.05 ; n=6$.

As shown in Figure 4A, PCLP composites made by the organic solvent-free method demonstrated superior cell proliferation compared with the composites prepared by solvent casting. Especially in the first 7 days, cells seeded on the PCLP scaffold grew rapidly while those on the solvent casting scaffold proliferated very slowly. This result may be due to the cytotoxicity of the residual organic solvent. These organic residues in the scaffolds may be harmful to adherent cells, growth factors, or nearby tissues. ${ }^{15,16}$ After 7 days of culture, cells seeded on PCLP scaffolds grew to a high confluence and their proliferation slowed. Meanwhile, the organic residues in the control group might have been removed after 2 changes of culture medium (the culture medium was changed every 3 days). Therefore, a delayed proliferation was observed in the control group after 7 days of culture.

Figure 4B shows that the presence of PCLP scaffolds did increase ALP activity of osteoblasts. On day 28, ALP activity in PCLP scaffolds reached a peak of $12.099 \pm 0.882$ units $/ g$ protein, and slightly deceased to $9.762 \pm 1.275$ units/g protein on day 35 . Using real-time quantitative PCR, we also noted
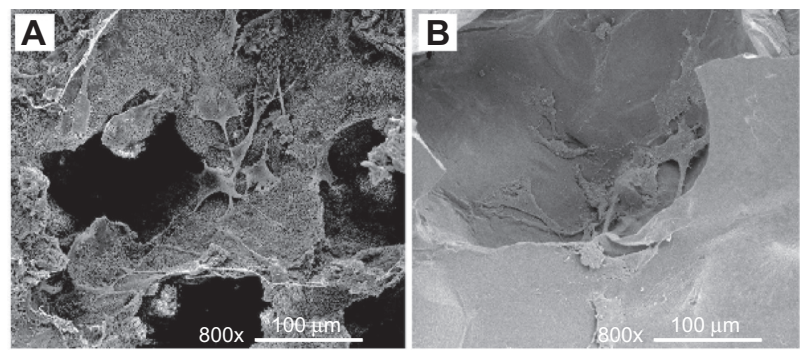

Figure 3 SEM images of osteoblasts cultured on the scaffolds for I day: (A) PCLP scaffold; (B) solvent casting scaffold.

Abbreviations: PCLP, powder mixing, compression molding, low-temperature treatment, and particulate leaching; SEM, scanning electron microscopy. that expression of osteogenic differentiation-associated genes was upregulated by PCLP scaffolds (Figure 4C, $4 \mathrm{D}$, and $4 \mathrm{E})$. These results were consistent with the report of Kim et al. ${ }^{8}$ There may be 2 reasons for this enhanced biological performance: first, the solvent-free methods we used during the fabricating process, and second, the refined surface structure of the scaffold. As shown in Figure 1C, $\beta$-TCP particles disperse homogenously in the PCLP scaffolds and become exposed directly to the cell. It has been proved that bioceramics enhance osteoblast differentiation as well as bone regeneration. ${ }^{17,18}$ In contrast, in the solvent casting process the mixing of ceramic with polymer solution followed by solvent evaporation resulted in coating of ceramic by a polymer layer (Figure 1D). This polymer layer may hinder the exposure of bioceramics and subsequently reduce the osteogenic induction of bioceramics. ${ }^{16}$

In the conventional sintering method, the solvent-free process can overcome the coating of ceramic by the polymer layer. ${ }^{19}$ Blending of polymer, ceramic, and salt followed by pressure with heating, a conventional heating method, can reduce the degree of ceramic coating compared with the solvent casting method. ${ }^{20}$ But coating of ceramics by polymer melting can still occur, because the polymer swells during melting in the limited space of the mold, and polymer solution flows into the spaces within ceramics under pressure. To reduce this negative effect, Jung et $\mathrm{al}^{16}$ introduced a method of separate pressing and thermal processes; however, this method may compromise the strength of the composite. In this study, we performed a number of experiments according to the properties of PLLA to determine the appropriate temperature and time of heat treatment. ${ }^{9}$ Moreover, the fabricating process was divided into 2 steps: heating and pressing. First, we chose $170^{\circ} \mathrm{C}$ as the preheating temperature and quickly pressed at a pressure of $10 \mathrm{MPa}$ for 5 minutes. Then the mixture was sintered at $200^{\circ} \mathrm{C}$ and pressed again. This process showed limited contact between $\beta$-TCP and polymer, leading to a minimum polymer coating, which results in superior osteoconduction to the osteoblast culture.

Another important factor affecting the ability of calcium phosphate-based materials to promote bone generation is grain size. It has been widely accepted that ceramics, metals, polymers, and composites with nanometer grain sizes can stimulate osteoblast activity, leading to faster bone formation, compared with micron grain sizes. ${ }^{21-23}$ In this study, the diameter of $\beta$-TCP particles used was around $1.31 \mu \mathrm{m}$ to $2.34 \mu \mathrm{m}$. In future studies, using nanoparticles may further improve scaffold properties. 
A

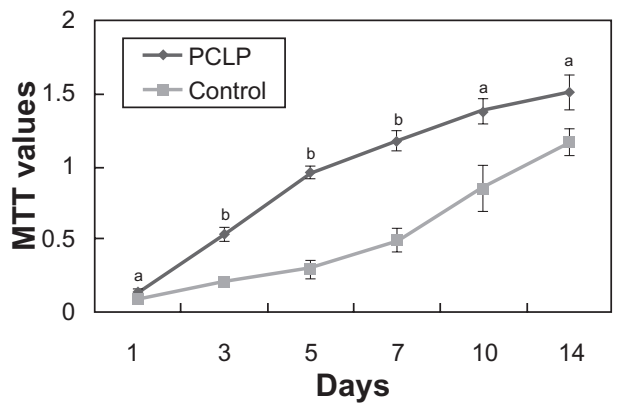

B

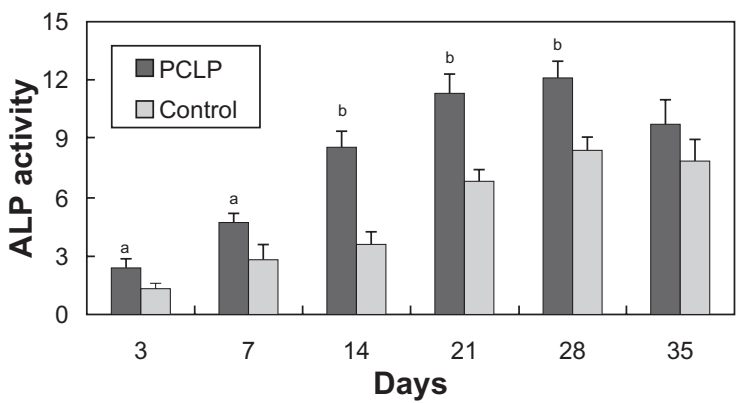

C

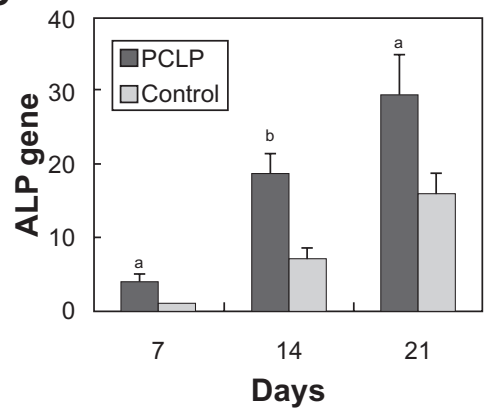

D

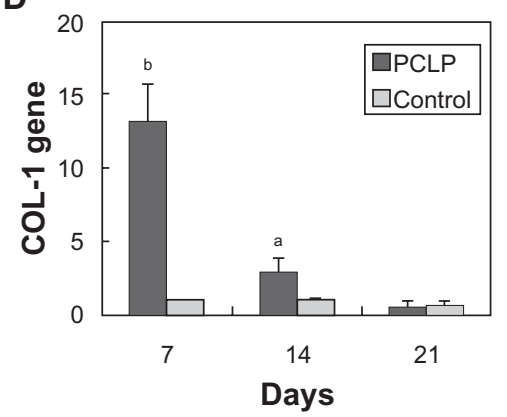

E

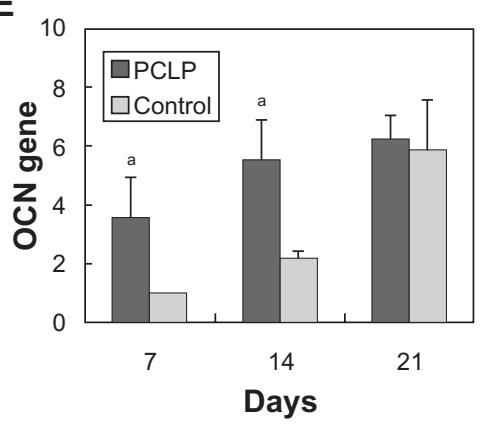

Figure 4 Results of in vitro tests: cell proliferation assessed by MTT method (A), ALP activity (B), and expression of osteogenic differentiation associated genes quantified by real-time RT-PCR (C, D, and E).

Notes: ${ }^{a} \mathrm{P}<0.05$; ${ }^{\mathrm{b}} \mathrm{P}<0.0 \mathrm{I} ; \mathrm{n}=3 \sim 6$.

Abbreviations: ALP, alkaline phosphatases; MTT, methylthiazol tetrazolium.

\section{Conclusion}

A novel PCLP method was successfully developed to prepare PLLA/ $\beta$-TCP scaffolds without using any organic solvent. The resultant scaffolds had high porosity with interconnected porous structure and high compressive strength. In vitro tests showed that cell proliferation, ALP activity, and osteogenic genes expression were significantly better for PCLP than for solvent casting scaffolds. Such a superior outcomes for the PCLP scaffolds can be attributed to the fact that this new method does not use any organic solvent. Its advantage is that it avoids the problems associated with solvent residues. As $\beta$-TCP particles disperse homogeneously in PLLA continuous phase matrix, the direct exposure of these particles to osteoblasts also stimulates cell proliferation and osteogenic differentiation.

\section{Acknowledgments}

We would like to thank Dr Malcom Xing, University of Manitoba, for valuable suggestions and manuscript editing.

\section{Disclosure}

The authors declare no conflicts of interest in relation to this work.

\section{References}

1. Cancedda R, Giannoni P, Mastrogiacomo M. A tissue engineering approach to bone repair in large animal models and in clinical practice. Biomaterials. 2007;28(29):4240-4250.

2. Piskin E. Biodegradable polymeric matrices for bioartificial implants. Int J Artif Organs. 2002;25(5):434-440.

3. Kim SS, Sun Park M, Jeon O, Yong Choi C, Kim BS. Poly(lactideco-glycolide)/hydroxyapatite composite scaffolds for bone tissue engineering. Biomaterials. 2006;27(8):1399-1409.

4. Kunze C, Freier T, Helwig E, et al. Surface modification of tricalcium phosphate for improvement of the interfacial compatibility with biodegradable polymers. Biomaterials. 2003;24(6):967-974.

5. Chen G, Ushida T, Tateishi T. Preparation of poly(L-lactic acid) and poly(DL-lactic-co-glycolic acid) foams by use of ice microparticulates. Biomaterials. 2001;22(18):2563-2567.

6. Nam YS, Park TG. Porous biodegradable polymeric scaffolds prepared by thermally induced phase separation. J Biomed Mater Res. 1999; 47(1):8-17.

7. Ho MH, Kuo PY, Hsieh HJ, et al. Preparation of porous scaffolds by using freeze-extraction and freeze-gelation methods. Biomaterials. 2004;25(1):129-138.

8. Kim HJ, Kim UJ, Vunjak-Novakovic G, Min BH, Kaplan DL. Influence of macroporous protein scaffolds on bone tissue engineering from bone marrow stem cells. Biomaterials. 2005;26(21): 4442-4452.

9. Kang Y, Yin G, Yuan Q, et al. Preparation of poly(L-lactic acid)/ beta-tricalcium phosphate scaffold for bone tissue engineering without organic solvent. Mater Lett. 2008;62(12-13):2029-2032.

10. Kang YQ, Xu XJ, Yin GF, et al. A comparative study of the in vitro degradation of poly(L-lactic acid)/beta-tricalcium phosphate scaffold in static and dynamic simulated body fluid. Eur Polym J. 2007;43(5): $1768-1778$. 
11. Hinoi E, Fujimori S, Nakamura Y, Yoneda Y. Group III metabotropic glutamate receptors in rat cultured calvarial osteoblasts. Biochem Biophys Res Commun. 2001;281(2):341-346.

12. Gauthier O, Bouler JM, Aguado E, Pilet P, Daculsi G. Macroporous biphasic calcium phosphate ceramics: influence of macropore diameter and macroporosity percentage on bone ingrowth. Biomaterials. 1998;19(1-3):133-139.

13. Hing KA, Best SM, Bonfield W. Characterization of porous hydroxyapatite. J Mater Sci Mater Med. 1999;10(3):135-145.

14. Mikos AG, Sarakinos G, Lyman MD, Ingber DE, Vacanti JP, Langer R. Prevascularization of porous biodegradable polymers. Biotechnol Bioeng. 1993;42(6):716-723.

15. Hile DD, Pishko MV. Solvent-free protein encapsulation within biodegradable polymer foams. Drug Deliv. 2004;11(5):287-293.

16. Jung Y, Kim SS, Kim YH, et al. A poly(lactic acid)/calcium metaphosphate composite for bone tissue engineering. Biomaterials. 2005; 26(32):6314-6322.

17. Chen Y, Mak AF, Wang M, Li JS, Wong MS. In vitro behavior of osteoblast-like cells on PLLA films with a biomimetic apatite or apatite/ collagen composite coating. J Mater Sci Mater Med. 2008;19(6): 2261-2268.
18. Link DP, van den Dolder J, van den Beucken JJ, et al. Evaluation of the biocompatibility of calcium phosphate cement/PLGA microparticle composites. J Biomed Mater Res A. 2008;87(3):760-769.

19. Wang M. Developing bioactive composite materials for tissue replacement. Biomaterials. 2003;24(13):2133-2151.

20. Ambrosio AM, Sahota JS, Khan Y, Laurencin CT. A novel amorphous calcium phosphate polymer ceramic for bone repair: I. Synthesis and characterization. J Biomed Mater Res. 2001;58(3):295-301.

21. Raimondo T, Puckett S, Webster TJ. Greater osteoblast and endothelial cell adhesion on nanostructured polyethylene and titanium. Int $J$ Nanomedicine. 2010;5:647-652.

22. Nelson M, Balasundaram G, Webster TJ. Increased osteoblast adhesion on nanoparticulate crystalline hydroxyapatite functionalized with KRSR. Int J Nanomedicine. 2006;1(3):339-349.

23. Webster TJ, Smith TA. Increased osteoblast function on PLGA composites containing nanophase titania. J Biomed Mater Res A. 2005; 74(4):677-686.
International Journal of Nanomedicine

\section{Publish your work in this journal}

The International Journal of Nanomedicine is an international, peerreviewed journal focusing on the application of nanotechnology in diagnostics, therapeutics, and drug delivery systems throughout the biomedical field. This journal is indexed on PubMed Central, MedLine, CAS, SciSearch $\AA$, Current Contents ${ }^{\circledR} /$ Clinical Medicine,

\section{Dovepress}

Journal Citation Reports/Science Edition, EMBase, Scopus and the Elsevier Bibliographic databases. The manuscript management system is completely online and includes a very quick and fair peer-review system, which is all easy to use. Visit http://www.dovepress.com/ testimonials.php to read real quotes from published authors. 